\title{
Evaluation of Different Quantitative Approaches for the Determination of Noneasily Ionizable Molecules by Different Atmospheric Pressure Interfaces Used in Liquid Chromatography Tandem Mass Spectrometry: Abamectin as Case of Study
}

\author{
Susana Grimalt, Óscar J. Pozo, Jose M. Marín, Juan V. Sancho, \\ and Félix Hernández \\ Research Institute for Pesticides and Water, University Jaume I, E-12071, Castellón, Spain
}

\begin{abstract}
The liquid chromatography tandem mass spectroscopy residue determination of compounds without any acidic or basic centers such as abamectin has been investigated. Several approaches regarding the interface used and adduct formation have been compared. The low acidity of the hydroxyl groups only made deprotonation feasible using the atmospheric pressure chemical ionization (APCI) interface. To obtain sufficient sensitivity for residue analysis, the Ion Sabre APCI interface was necessary. However, the sensitivity attained was lower than for monitoring adducts in positive ion mode. Using electrospray ionization, different adducts with $\mathrm{Na}^{+}, \mathrm{NH}_{4}^{+}$, and $\mathrm{Li}^{+}$were tested and compared. The best results were obtained for the ammoniated adduct in electrospray ionization (ESI) because of its high sensitivity and the presence of several product ions with similar abundance. The highest sensitivity was reached using an in-source fragment as precursor ion, leading to a limit of detection (LOD) of $2 \mu \mathrm{g} / \mathrm{L}$ with low relative standard deviation. The relatively high abundance of other transitions allowed abamectin confirmation at concentrations close to the LOD $(6 \mu \mathrm{g} / \mathrm{L})$. Alkali ions were found to be a suitable alternative to determine and confirm abamectin at residue levels. The $[\mathrm{M}+\mathrm{Na}]^{+}$also presented various product ions with similar abundance, which allowed confirmation at LOD levels. However, this LOD was found to be almost four times higher than with $\left[\mathrm{M}+\mathrm{NH}_{4}\right]^{+}$because of the poor sensitivity of the transitions obtained. Although the use of $\mathrm{Li}^{+}$facilitated the fragmentation of the adduct $[\mathrm{M}+$ $\mathrm{Li}]^{+}$, with similar sensitivity to $\left[\mathrm{M}+\mathrm{NH}_{4}\right]^{+}$, this fragmentation preferentially generated only one product ion, which did not allow confirmation at concentration levels lower than $15 \mu \mathrm{g} / \mathrm{L}$. The use of APCI for monitoring adducts was also feasible, but with less sensitivity. The sensitivity increased with the Ion Sabre APCI, although it was still five times lower than with ESI. Other adduct formers such as $\mathrm{Co}^{2+}$ and $\mathrm{Ni}^{2+}$ also were tested with unsatisfactory results. (J Am Soc Mass Spectrom 2005, 16, 1619-1630) (c) 2005 American Society for Mass Spectrometry
\end{abstract}

$\mathrm{T}$ The atmospheric pressure ionization (API) interface development for liquid chromatography coupled to mass spectrometry (LC/MS) is an important advance for residue determination in analytical chemistry. This powerful analytical tool provides a solution for determining many compounds that are not amenable to analysis by gas chromatography (GC) as a

Published online August 22, 2005

Address reprint requests to Félix Hernández, Research Institute for Pesticides and Water, University Jaume I, E-12071, Castellón, Spain. E-mail: hernandf@exp.uji.es result of their thermal instability and polarity [1]. In some cases, the use of LC with conventional detectors (UV, fluorescence or electrochemical detection) could be an alternative, but it frequently lacks sufficient selectivity and sensitivity for residue determination in complex matrices.

Two API interfaces, atmospheric pressure chemical ionization (APCI) and electrospray ionization (ESI), have been widely used in the last 5 years [2] in the biochemical, biotechnological [3], and environmental fields $[1,4,5]$. These interfaces have allowed the development of methods for determination of compounds 
that present physicochemical characteristics incompatible with other analytical techniques, such as GC-MS or LC-UV. However, the use of API interfaces has drawbacks that are related mainly to the need for basic or acidic centers in the analyte. The absence of these can hinder the ionization necessary for obtaining a satisfactory quantitative analytical method. This is the case with compounds such as polycyclic aromatic hydrocarbons (PAH) or organochlorinated (OC) or polyoxygenated compounds. Although GC-MS is a suitable technique for the selective and sensitive determination of PAHs [6] and OCs [7, 8], the high molecular mass, polarity, and low volatility of polyoxygenated compounds prevents the use of this approach [9].

LC-API-MS appears to offer the best option for the quantification and confirmation of low levels of polyoxygenated compounds, in spite of the absence of an acidic or basic center. The presence of hydroxyl groups in some analytes could make deprotonation possible in the negative APCI mode, because of its efficient ionization of compounds with low polarity [10-12]. But the more general choice is adduct formation by the addition of different types of additives in the mobile phase, because this approach allows the use of both APCI and ESI interfaces.

Adduct ion formation generally is favored more in ESI than in APCI. The most common ions for adduct formation in the ESI source are alkali metal ions, such as sodium and potassium. These exhibit strong affinity to oxygenated centers (ether, ester, carboxylic, or alcohol groups) and frequently are present as impurities in the mobile phase, the extraction solvents, or even in the determination system. Although these ions can generate valuable information in qualitative applications [13], their use in quantitative methods is highly restricted due to insufficient fragmentation and poor reproducibility. Thus, $[\mathrm{M}+\mathrm{Na}]^{+}$used to be discarded when developing quantitative methods [14]. The most valuable alternative to $[\mathrm{M}+\mathrm{Na}]^{+}$is the use of ammonium adducts after adding volatile ammonium salts as an additive in the mobile phase. Ammonium adducts present several advantages including usually easier fragmentation [15] and the possibility of using both API interfaces [16-18]. Different primary amines also have been tested for this purpose [16].

Other alternatives to the use of $[\mathrm{M}+\mathrm{Na}]^{+}$have been tested that favor the formation of adducts with monocharged metals such as $[\mathrm{M}+\mathrm{Li}]^{+}[19-22],[\mathrm{M}+\mathrm{Cs}]^{+}[19$, $21,22],[\mathrm{M}+\mathrm{Rb}]^{+}[22]$, or $[\mathrm{M}+\mathrm{Ag}]^{+}$[23] and doubly charged metals such as calcium [24], magnesium [24], cobalt [24, 25], zinc [21, 25, 26], copper [25], or nickel [21, 25]. Through these approaches valuable conclusions have been obtained in qualitative applications but their use for quantitative purposes still is very limited.

Macrocyclic lactones can be included within the polyoxygenated compound group. Abamectin is an insecticide that belongs to the macrocyclic lactone class of avermectins and consists of a mixture of two homologous compounds, avermectin $\mathrm{B}_{1 \mathrm{a}}(>80 \%)$ and aver- mectin $\mathrm{B}_{1 \mathrm{~b}}(<20 \%)$ [27]. Some LC-MS and liquid chromatography tandem mass spectrometry (LC-MS/MS) methods have been published for abamectin, using both ESI and APCI sources. Most were based on adduct formation by ESI in positive mode, mainly ammonium $[28,29]$ or sodium $[27,30,31]$ adducts. Some authors have developed quantitative [11] and confirmatory [1012] analytical methods for avermectins, measuring the deprotonated compounds in negative mode using APCI. Others [32] developed methods using APCI in positive mode, based on $\left[\mathrm{M}+\mathrm{NH}_{4}\right]^{+}$formation. The fact that abamectin is not easily ionizable has resulted in different approaches being used, and no agreement exists on the best way to determine this compound at low concentration levels. Other interesting approaches such as $[\mathrm{M}+\mathrm{Li}]^{+}$still have not been tested.

Our objective in this study is to give a comprehensive overview on the critical influence of the use of different ions or adducts to achieve reproducible ionization. Reproducible ionization would allow the development of sensitive analytical methods based on LCMS/MS. For this purpose, we evaluated different ionization parameters and API sources (ESI, APCI and the Ion Sabre APCI). The deprotonation of hydroxyl groups as well as the formation of different adducts are compared for the determination of abamectin. The use of various mobile-phase additives is considered to promote adduct molecule ions, with the purpose of providing the basis for a robust, reproducible, quantitative, and confirmative method at residue level in citrus fruits.

\section{Experimental Procedures}

\section{Reagents and Chemicals}

Abamectin analytical reference standard was purchased from Dr. Ehrenstorfer (Augsburg, Germany). Lithium acetate dihydrate $\left(\mathrm{LiOAc} \cdot 2 \mathrm{H}_{2} \mathrm{O},>63 \%\right)$, cobalt(II) acetate tetrahydrate (CoOAc $\cdot 4 \mathrm{H}_{2} \mathrm{O},>98 \%$ ), and triethylamine $\left(\left(\mathrm{C}_{2} \mathrm{H}_{5}\right)_{3} \mathrm{~N},>99 \%\right)$ were obtained from Sigma (St. Louis, MO). Nickel acetate (NiOAc $\cdot 4 \mathrm{H}_{2} \mathrm{O},>98 \%$ ) was obtained from Panreac (Barcelona, Spain). Sodium acetate anhydrous (NaOAc, >99\%), ammonium acetate $\left(\mathrm{NH}_{4} \mathrm{OAc},>98 \%\right)$, high-performance liquid chromatography (HPLC)-grade acetonitrile and HPLC-grade methanol were supplied by ScharLab (Barcelona, Spain). LC-grade water was obtained by purifying demineralized water in a Nanopure II system (Barnstead, Newton, MA).

Standard stock solution was prepared by dissolving abamectin in acetonitrile to a final concentration of 500 $\mu \mathrm{g} / \mathrm{mL}$. For both LC-MS analysis and sample fortification, the stock solution was diluted with acetonitrile.

Salts were prepared separately dissolving the necessary amount in $25 \mathrm{~mL}$ of water to obtain a final concentration of $500 \mathrm{mM}(1.04 \mathrm{~g}$ of $\mathrm{NaOAc}, 2.02 \mathrm{~g}$ of $\mathrm{LiOAc} \cdot 2 \mathrm{H}_{2} \mathrm{O}, 3.18 \mathrm{~g}$ of $\mathrm{CoOAc} \cdot 4 \mathrm{H}_{2} \mathrm{O}, 0.98 \mathrm{~g}$ of 
$\mathrm{NH}_{4} \mathrm{OAc}, 1.28 \quad g$ of $\left(\mathrm{C}_{2} \mathrm{H}_{5}\right)_{3} \mathrm{~N}$, and $3.17 \mathrm{~g}$ of $\mathrm{NiOAc} \cdot 4 \mathrm{H}_{2} \mathrm{O}$ ).

\section{Instrumentation}

An LC system Waters Alliance 2795 (Waters, Milford, $\mathrm{MA}$ ) was interfaced to a triple quadrupole mass spectrometer. The LC separation was performed using two $\mathrm{X}$-Terra columns (both from Waters) with different dimensions depending on the interface: an X-Terra MS $\mathrm{C}_{18}, 5 \mu \mathrm{m}, 50 \times 4.6-\mathrm{mm}$ inner diameter (i.d.) for APCI and Ion Sabre APCI at a flow rate of $0.8 \mathrm{~mL} / \mathrm{min}$; and an X-Terra $\mathrm{MS} \mathrm{C}_{18}, 3.5 \mu \mathrm{m}, 50 \times 1.0-\mathrm{mm}$ i.d. for ESI at a flow rate of $60 \mu \mathrm{L} / \mathrm{min}$. The mobile phases used were an HPLC water/HPLC methanol gradient, both containing an additive when necessary, where the percentage of organic solvent changed linearly as follows: 0 min, 35\%; 2 min, 35\%; 7 min, 90\%; $14 \mathrm{~min}, 90 \%$; 14.1 $\mathrm{min}, 35 \%$, in ESI, and $0 \mathrm{~min}, 35 \%$; $2 \mathrm{~min}, 35 \%$; $7 \mathrm{~min}$, 90\%; $8 \mathrm{~min}, 90 \%$; $8.1 \mathrm{~min}, 35 \%$, in APCI.

A Quattro Micro API (quadrupole-hexapole-quadrupole, Waters) mass spectrometer with three different interfaces was used; ESI, APCI and an Ion Sabre APCI (Waters). Drying gas as well as nebulizing gas was nitrogen generated from pressurized air in a highpurity nitrogen generator NM30LA Gas Station from Peak Scientific (Inchinnan, Scotland). For ESI, the desolvation gas flow and cone gas flow were selected $\sim 600$ and $60 \mathrm{~L} / \mathrm{h}$, respectively. For APCI and Ion Sabre, the desolvation gas and cone gas were set at a flow of 200 and $40 \mathrm{~L} / \mathrm{h}$, respectively.

Infusion experiments were performed using the built-in syringe pump at a flow rate of $10 \mu \mathrm{L} / \mathrm{min}$ for ESI and the Alliance 2795 at a flow rate of $0.8 \mathrm{~mL} / \mathrm{min}$ for APCI.

To operate in MS/MS mode, collision gas was Argon 99.995\% (Carburos Metalicos, Valencia, Spain) with a pressure of $3 \cdot 10^{-3} \mathrm{mbar}$ in the collision cell. Capillary (ESI) voltages of $3.5 \mathrm{kV}$ and current intensity in Corona (APCI) of $25 \mu \mathrm{A}$ were used. The desolvation temperature for ESI was set to $350{ }^{\circ} \mathrm{C}$ and the source temperature was set to $120^{\circ} \mathrm{C}$, and in the case of APCI, source temperature was selected at $130{ }^{\circ} \mathrm{C}$ and APCI probe temperature was set at $450^{\circ} \mathrm{C}$. Dwell times of $0.2 \mathrm{~s} / \mathrm{scan}$ were chosen. Solvent delay was selected at $9 \mathrm{~min}$ (ESI) and $5 \mathrm{~min}$ (APCI) to give an additional cleanup using the built-in divert valve controlled by the Masslynx NT v. 4.0 software (Waters). The Quanlynx application manager (Waters) was used to process the quantitative data obtained from calibration standards and from orange samples.

\section{Sample Procedure}

Whole orange samples were cut into small pieces without any pretreatment and were triturated. Homogenized orange sample $(25 \mathrm{~g})$ was accurately weighted (precision, $0.1 \mathrm{mg}$ ) and mixed with $80 \mathrm{~mL}$ of HPLC acetonitrile. After extraction for 2 min with a high- speed blender Ultra-Turrax T25 (Janke \& Kunkel, Staufen, Germany) at $8000 \mathrm{rpm}$, the entire extract was filtered through a filter paper and washed with HPLC acetonitrile. Finally, the volume was adjusted to $100 \mathrm{~mL}$ with HPLC acetonitrile. Fortification of the extracts was performed after the extraction procedure at the 200$\mu \mathrm{g} / \mathrm{L}$ concentration level. Analyses were performed using the LC-ESI-MS/MS system described previously, by direct injection of orange extracts: $3 \mu \mathrm{L}$ for ESI and $50 \mu \mathrm{L}$ for APCI and Ion Sabre APCI.

\section{Results and Discussion}

\section{Optimization of MS Conditions}

Different hydroxy-macrocyclic lactones have been determined either by negative ionization mode, especially for ${ }^{\circ}$ phenolic ${ }^{\circ}$ compounds $\left[11,{ }^{\circ} 12\right],{ }^{\circ}{ }^{\circ}{ }^{\circ} b^{\circ}{ }^{\circ}$ positive ${ }^{\circ}$ ionization $^{\circ}$ mode, ${ }^{\circ}$ when ${ }^{\circ}{ }^{\circ}{ }^{\circ}$ mine $^{\circ}$ group $^{\circ}$ was $^{\circ}$ present ${ }^{\circ}[33] .{ }^{\circ}$ For abamectin, its chemical structure made its deprotonation feasible due to the presence of three hydroxyl groups and therefore its determination by negative ionization was possible. The absence of basic centers prevents the direct determination of abamectin as a protonated ion. Therefore, the use of triethylamine $\left(\mathrm{Et}_{3} \mathrm{~N}\right)$ as a proton scavenger was tested in negative ionization mode whereas the formation of adducts with sodium, ammonium, lithium, nickel, and cobalt was promoted in positive ionization mode by the addition

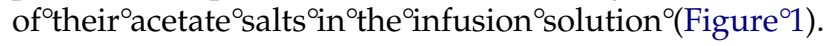
Results regarding ionization and fragmentation were compared and discussed. Additionally, possible fragmentation ${ }^{\circ}$ pathways ${ }^{\circ}$ have ${ }^{\circ}$ been ${ }^{\circ}$ proposed $^{\circ}$ (Figures $\left.{ }^{\circ}-4\right)$, although these hypotheses would need to be supported by isotope labeling, $\mathrm{MS}^{\mathrm{n}}$, or theoretical calculations.

\section{Chromatographic Signal Optimization}

To make all the chromatographic experiences comparable, two X-Terra columns were used with internal diameter, flow rate, and injection volume optimized for ESI and APCI, respectively. These columns allowed us to use all additives tested, including the relatively basic $\mathrm{Et}_{3} \mathrm{~N}$, because of their high-working $\mathrm{pH}$. Although a comparison between ESI and APCI, regarding differences in absolute sensitivity, could have been performed in terms of picograms on column, the aim of this study was to compare both interfaces from a practical point of view and therefore we used injected concentration $(\mu \mathrm{g} / \mathrm{mL})$ for the comparison.

When working with adduct formation in API interfaces, two opposite effects must be considered. On one hand, the presence of small amounts of adduct cation in the mobile phase is necessary to promote the formation of the $[\mathrm{M}+\mathrm{X}]^{+}$. But on the other hand, the presence of these salts in the mobile phase can produce ionization suppression, drastically reducing the sensitivity of the method. Therefore, the additive concentration in the mobile phase has to be optimized to balance both 

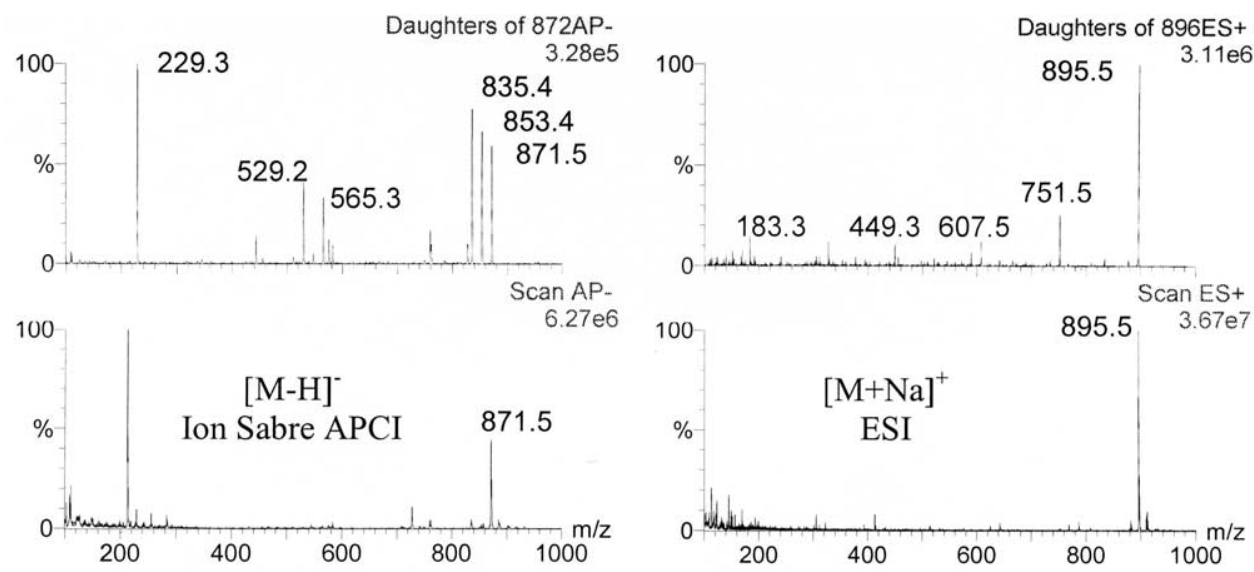

(a)
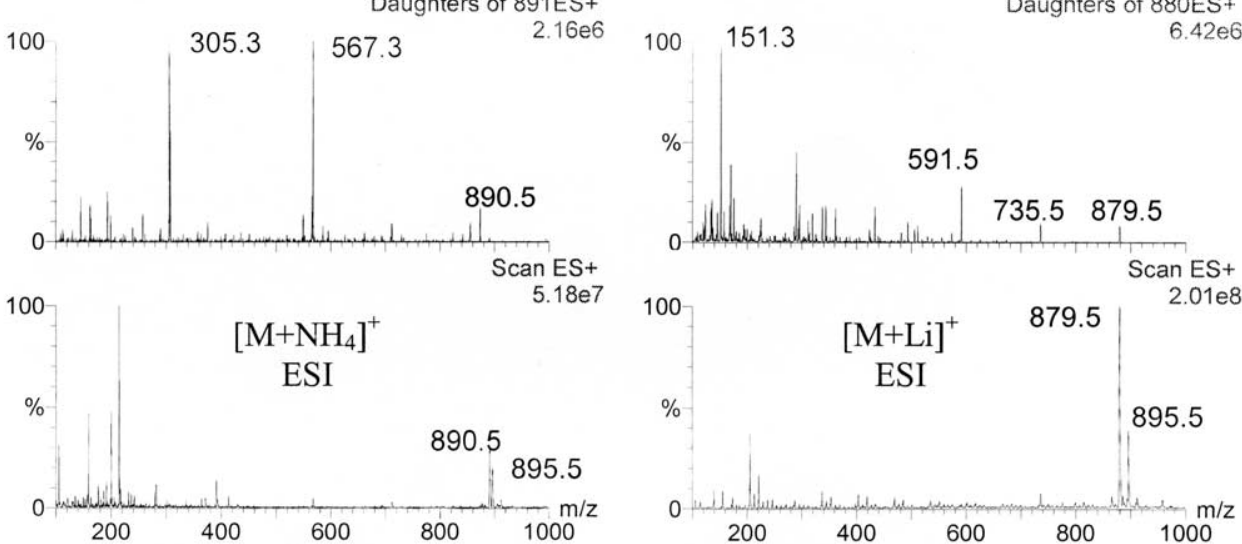

(c)

(d)

Figure 1. Full scan mass spectrum (bottom) and product ion spectra (top) of abamectin in different conditions acquired by infusion of $4.5 \mu \mathrm{g} / \mathrm{mL}$ of standard solution. (a) Negative Ion Sabre APCI 5-mM $\mathrm{Et}_{3} \mathrm{~N}$, (b) positive ESI without any additive, (c) positive ESI 1-mM NH $\mathrm{H}_{4} \mathrm{Oac}$, and (d) positive ESI 1-mM LiOAc.

effects. Results obtained for this optimization, in all approaches tested in the spiked orange extract, are shown ${ }^{\circ}{ }^{\circ}$ Table $^{\circ} 1$.

To obtain a quantitative and confirmative method, the following aspects have to be taken into account: (i) possible matrix effect produced by co-eluted components of the matrix, (ii) the reproducibility of the method, and (iii) the possibility of recording more than one sensitive transition to confirm positive samples. In the case of abamectin residue determination in orange samples, no appreciable matrix effect was observed (recoveries were between 80 and 110\%) and, therefore, this effect has not been discussed here. This study focused on sensitivity, reproducibility, and the possibility of confirming positives in samples. To confirm the identity of an analyte, a minimum of two transitions needs ${ }^{\circ}$ to $^{\circ}$ be $^{\circ}$ acquired $^{\circ}[34]^{\circ}:^{\circ}{ }^{\circ}$ quantitative $^{\circ} \operatorname{transition}^{\circ}(Q)$ and at least one confirmative transition $(q)$. A ratio calculation between quantitative and confirmative transition intensities was made by dividing the responses of $Q$ by $q$. Similar sensitivity for both transitions $(Q$ and $q$ ) is desirable for confirmation at low concentrations, preferably ${ }^{\circ} \mathrm{at}^{\circ}$ the $\mathrm{Iimit}^{\circ}$ of $^{\circ} \operatorname{detection}^{\circ}(\mathrm{LOD}){ }^{\circ}$ level. ${ }^{\circ}$ Table $^{\circ}$ shows the relative standard deviation (RSD) and the average $Q / q$ ratio $(n=10)$ obtained for all approaches tested in orange extracts spiked with abamectin at 200 $\mu \mathrm{g} / \mathrm{L}$ level. The closer the $Q / q$ value is to one, the better the method for confirmative purposes at low residue levels.

\section{Negative Ionization}

When checking ESI in negative ionization mode no [M $\mathrm{H}^{-}$was obtained even after addition of $\mathrm{Et}_{3} \mathrm{~N}$. Only a weak peak corresponding to the acetate adduct ([M + $\left.\mathrm{CH}_{3} \mathrm{COO}\right]^{-}$) was obtained after adding ammonium acetate, but the low intensity of this peak made it unadvisable to use this for quantitative analysis at the residue level.

On the other hand, although the use of conventional APCI allowed the deprotonation of abamectin, the sensitivity was not enough for residue determination, necessitating the use of Ion Sabre APCI to obtain satisfactory ${ }^{\circ}$ results. ${ }^{\circ}$ Figure $^{\circ} 1 a^{\circ}$ shows $^{\circ}$ Ion $^{\circ}$ Sabre $^{\circ}$ APCI spectra for abamectin in mass spectrometry (bottom) and MS/MS (top) mode by infusion of $4.5 \mu \mathrm{g} / \mathrm{mL}$ of standard solution. The mass spectrometry spectrum 


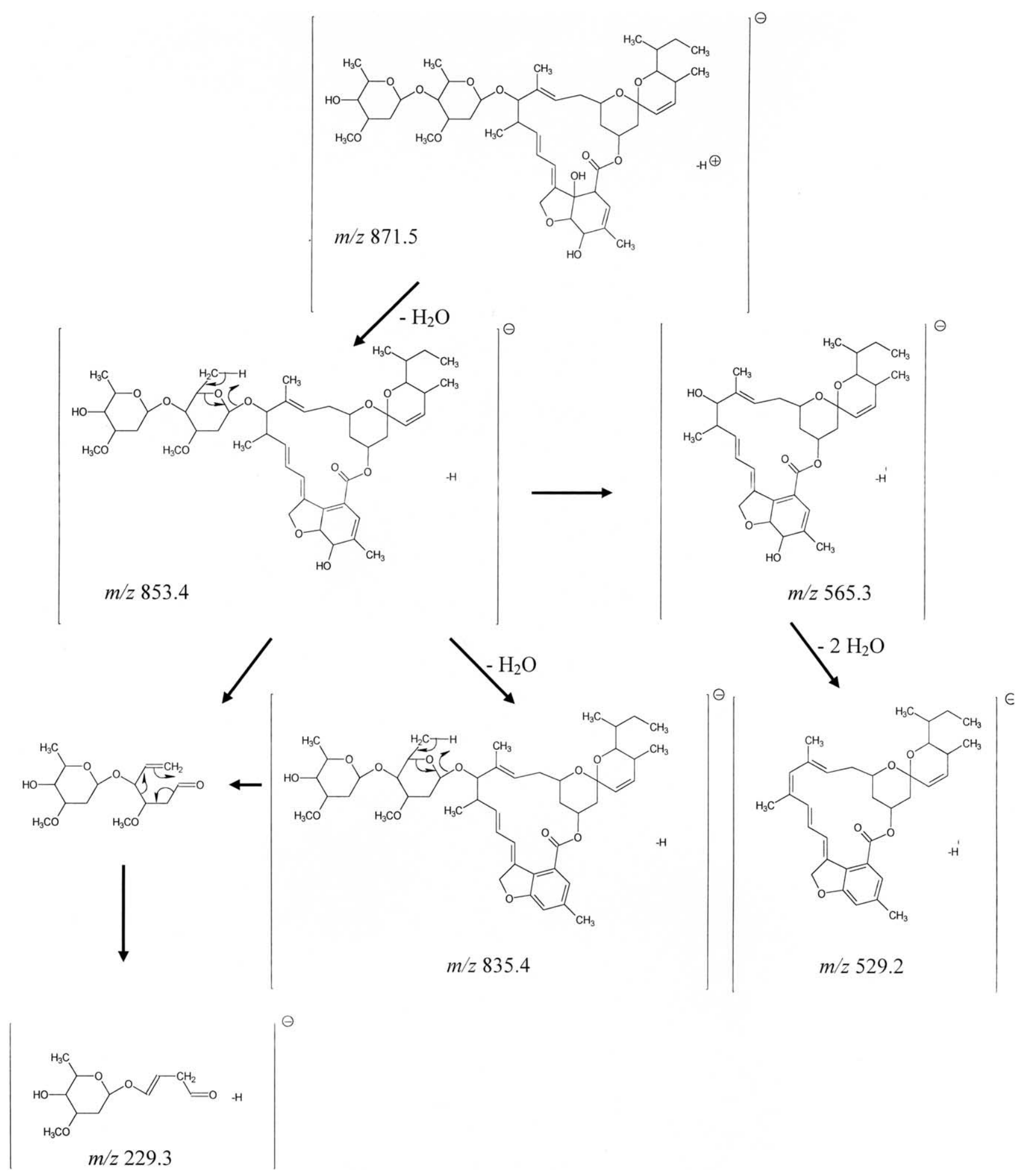

Figure 2. Proposed fragmentation pathway for abamectin in negative APCI.

presents an abundant peak at $\mathrm{m} / \mathrm{z} 871.5$, corresponding to the $[\mathrm{M}-\mathrm{H}]^{-}$ion optimized at a cone voltage of $35 \mathrm{~V}$.

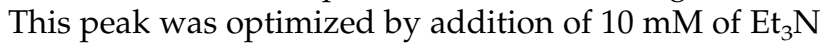
to increase the deprotonation, confirming the low acidity of these hydroxyl groups. Regarding the MS/MS spectrum, five important product ions were obtained.
Two of them $(\mathrm{m} / \mathrm{z} 853.4$ and 835.4 , optimized at a collision energy of $20 \mathrm{eV}$ ) presented low specificity for the determination because they can be assigned to the neutral losses of one and two water molecules, respectively $\left(\left[\mathrm{M}-\mathrm{H}-\mathrm{H}_{2} \mathrm{O}\right]^{-}\right.$and $\left.\left[\mathrm{M}-\mathrm{H}-2 \mathrm{H}_{2} \mathrm{O}\right]^{-}\right)$, as can be $^{\circ}$ seen $^{\circ}$ in $^{\circ}$ Figure $^{\circ} 2 .{ }^{\circ}$ The $^{\circ}$ other $^{\circ}$ product $^{\circ}$ ions ${ }^{\circ}$ showed 


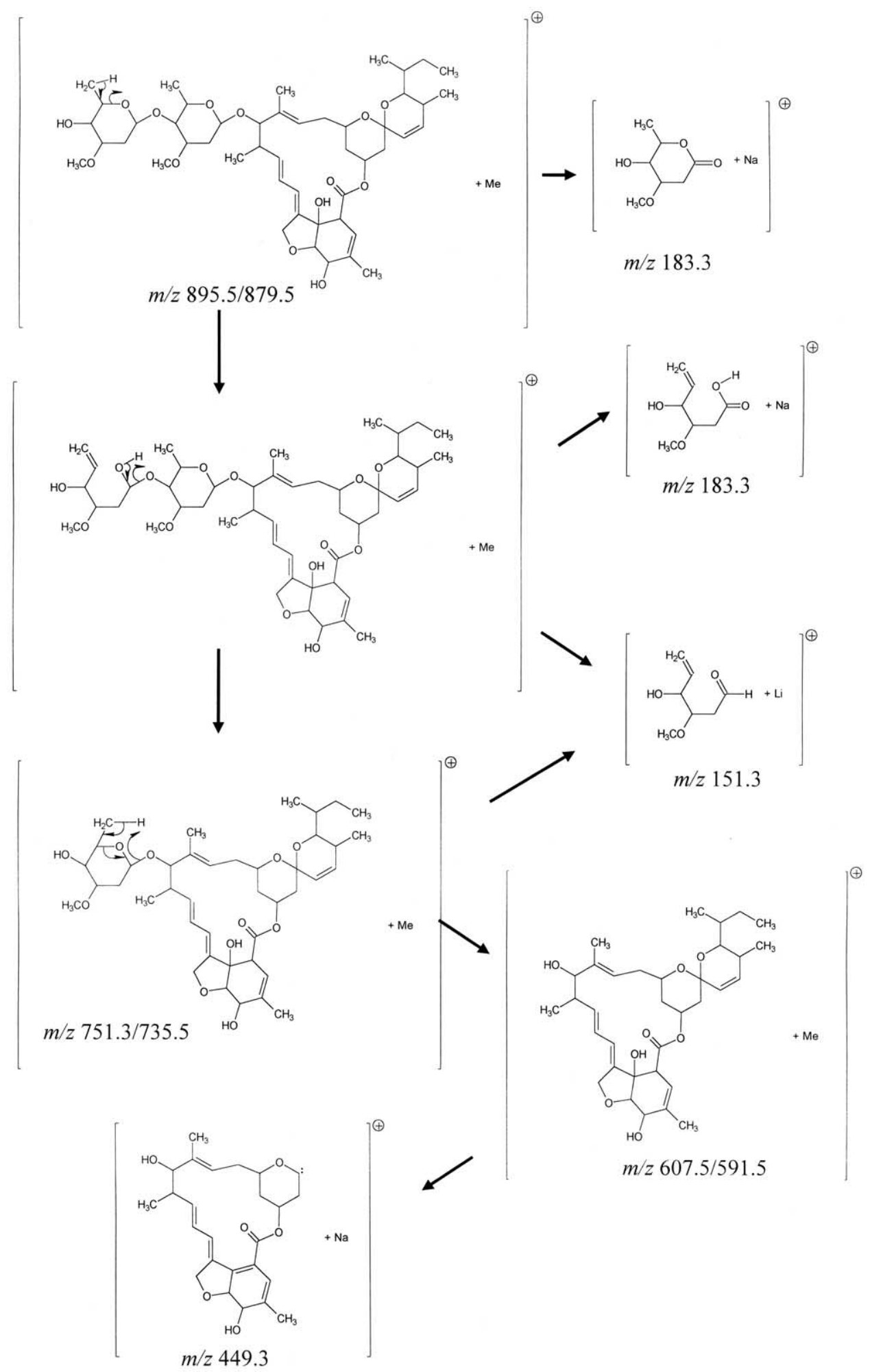

Figure 3. Proposed fragmentation pathway for abamectin in positive ESI with metal adducts $(\mathrm{Me}=$ $\mathrm{Na}^{+}$or $\left.\mathrm{Li}^{+}\right)$.

higher specificity because they may imply the loss of monosaccharides (fragments at $\mathrm{m} / \mathrm{z} 565.3$ and 529.2 optimized at $30 \mathrm{eV}$ and $25 \mathrm{eV}$, respectively) or even the rupture of the lactone ring $(\mathrm{m} / \mathrm{z} 229.2$ optimized at 30
$\mathrm{eV})$. This higher specificity suggested the use of the last three transitions to develop quantitative methods.

When applying this approach after chromatography, a peak was obtained without adding any addi- 


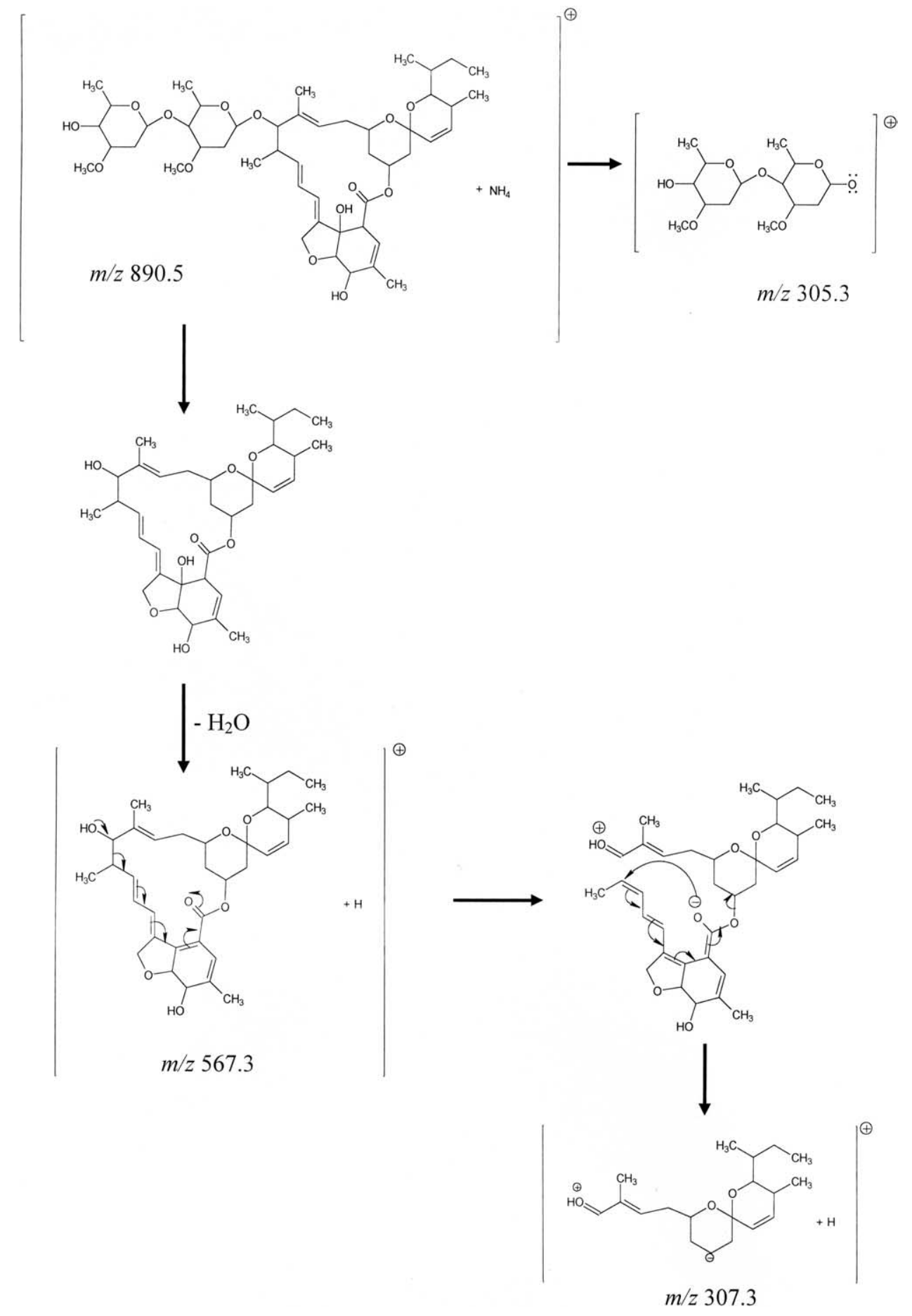

Figure 4. Proposed fragmentation pathway for abamectin in positive ESI with ammonium adducts.

tive in the mobile phase (estimated LOD of 100 $\mu \mathrm{g} / \mathrm{L})$. The sensitivity increased around three times after $\mathrm{Et}_{3} \mathrm{~N}$ addition although it was still lower than in other $^{\circ}$ approaches $^{\circ}$ tested $^{\circ}\left(\right.$ Figure $\left.^{\circ} 5 \mathrm{a}\right) .^{\circ}$ The $^{\circ}$ optimum $^{\circ}$ concentration of $\mathrm{Et}_{3} \mathrm{~N}^{\circ}$ was ${ }^{\circ}$ found ${ }^{\circ}$ to ${ }^{\circ} \mathrm{be}^{\circ} 500^{\circ} \mu \mathrm{M}^{\circ}$ (Table $\left.{ }^{\circ} 1\right)$. $\mathrm{As}^{\circ} \mathrm{can}^{\circ} \mathrm{be}^{\circ}$ seen $^{\circ}{ }^{\circ}{ }^{\circ} \mathrm{Table}^{\circ} 2,{ }^{\circ}$ satisfactory $^{\circ} \mathrm{RSD}^{\circ}{ }^{\circ}$ alues ${ }^{\circ}$ were obtained $^{\circ}$ and $^{\circ} \mathrm{a}^{\circ} \mathrm{Q} / q$ ratio ${ }^{\circ}$ of ${ }^{\circ}$ around ${ }^{\circ}$ two $^{\circ}$ was $^{\circ}$ achieved with ${ }^{\circ}$ this ${ }^{\circ}$ approach, ${ }^{\circ}$ facilitating ${ }^{\circ}$ the ${ }^{\circ}$ confirmation ${ }^{\circ}$ of $^{\circ}$ posi- tive samples at concentrations near the LOD of the method (around $30 \mu \mathrm{g} / \mathrm{L}$ ). The low sensitivity in negative mode ${ }^{\circ}$ also ${ }^{\circ}$ has ${ }^{\circ}$ been ${ }^{\circ}$ addressed ${ }^{\circ}$ by $^{\circ} Z_{\text {Zywitz }}{ }^{\circ} \mathrm{e}^{\circ}{ }^{\circ}{ }^{\circ} .[28]^{\circ},{ }^{\circ}$ who did not consider this approach for residue determination of abamectin. The results of our work show that the use of the Ion Sabre APCI interface together with the addition of $\mathrm{Et}_{3} \mathrm{~N}$ improved the method sensitivity, although this approach is still inadequate for abamectin residue determi- 
Table 1. Optimization of the mobile-phase buffer for each species studied

\begin{tabular}{|c|c|c|c|}
\hline API interface & Species & $\begin{array}{c}\text { Mobile-phase } \\
\text { conditions } \\
(\mu \mathrm{M})\end{array}$ & $\begin{array}{l}\mathrm{LOD}^{\mathrm{a}} \\
(\mu \mathrm{g} / \mathrm{L})\end{array}$ \\
\hline \multirow{5}{*}{ APCl-ion Sabre } & \multirow[t]{5}{*}[\mathrm{M}-\mathrm{H}]{$^{-}$} & $10 \mathrm{Et}_{3} \mathrm{~N}$ & 67 \\
\hline & & $100 \mathrm{Et}_{3} \mathrm{~N}$ & 37 \\
\hline & & $500 \mathrm{Et}_{3} \mathrm{~N}$ & 29 \\
\hline & & $5,000 \mathrm{Et}_{3} \mathrm{~N}$ & 36 \\
\hline & & $10,000 \mathrm{Et}_{3} \mathrm{~N}$ & nd \\
\hline \multirow[t]{10}{*}{$\mathrm{ESI}+$} & \multirow[t]{3}{*}[\mathrm{M}+\mathrm{Na}]{$^{+}$} & $1 \mathrm{NaOAc}$ & 22 \\
\hline & & $10 \mathrm{NaOAc}$ & 7 \\
\hline & & $50 \mathrm{NaOAc}$ & 10 \\
\hline & \multirow[t]{4}{*}[\mathrm{M}+\mathrm{NH}_{4}]{$^{+}$} & $10 \mathrm{NH}_{4} \mathrm{OAc}$ & 3 \\
\hline & & $100 \mathrm{NH}_{4} \mathrm{OAc}$ & 2 \\
\hline & & $500 \mathrm{NH}_{4} \mathrm{OAc}$ & 3 \\
\hline & & $5,000 \mathrm{NH}_{4} \mathrm{OAc}$ & 9 \\
\hline & \multirow[t]{3}{*}[\mathrm{M}+\mathrm{Li}]{$^{+}$} & $5 \mathrm{LiOAc}$ & 13 \\
\hline & & $10 \mathrm{LiOAc}$ & 3 \\
\hline & & $50 \mathrm{LiOAc}$ & 4 \\
\hline \multirow[t]{4}{*}{$\mathrm{APCl}+$ Ion Sabre } & \multirow[t]{4}{*}[\mathrm{M}+\mathrm{NH}_{4}]{$^{+}$} & $10 \mathrm{NH}_{4} \mathrm{OAc}$ & 30 \\
\hline & & $100 \mathrm{NH}_{4} \mathrm{OAc}$ & 14 \\
\hline & & $500 \mathrm{NH}_{4} \mathrm{OAC}$ & 10 \\
\hline & & $5,000 \mathrm{NH}_{4} \mathrm{OAc}$ & 12 \\
\hline
\end{tabular}

The optimum conditions regarding sensitivity are marked in grey. nd $=$ not detected.

aLOD estimated from the most sensitive transition. $871.5>229.3$ for [M $-\mathrm{H}^{-}, 895.5>751.3$ for $[\mathrm{M}+\mathrm{Na}]^{+}, 567.3>307.3$ for $\left[\mathrm{M}+\mathrm{NH}_{4}\right]^{+}$, and $879.5>151.3$ for $[\mathrm{M}+\mathrm{Li}]^{+}$

nation without a preconcentration step during sample treatment.

\section{Sodium Adducts}

Sodium adducts are the most commonly formed in LC-MS-based methods. Their presence in spectra is frequent even without adding any additive in the infusion solution, possibly because of small amounts of this cation in solvents, pipettes, etc. This was the case $^{\circ}$ for $^{\circ}$ abamectin, $^{\circ}$ where ${ }^{\circ}$ the $^{\circ}$ high $^{\circ}$ affinity $^{\circ}$ of ${ }^{\circ}$ the polyoxygenated structure for sodium allowed us to optimize MS conditions without using any additive. Figure $^{\circ} 1 b^{\circ}$ shows $^{\circ}$ the ${ }^{\circ}$ mass $^{\circ}$ spectrometry ${ }^{\circ}$ and $^{\circ}$ the MS/MS ESI spectra for abamectin. In the mass spectrometry spectrum, an abundant $[\mathrm{M}+\mathrm{Na}]^{+}$ion was observed at $m / z$ 895.5, with infusion in a methanol/ water medium optimized at high cone voltage $(90 \mathrm{~V})$. The high intensity of the $[\mathrm{M}+\mathrm{Na}]^{+}$ion can make the use of these adducts for quantitative determination advisable. However, when MS/MS experiments were performed, ${ }^{\circ}$ poor $^{\circ}$ fragmentation ${ }^{\circ}$ was $^{\circ}{ }^{\circ}$ bserved ${ }^{\circ}$ (Figure $1 b,{ }^{\circ}$ top $)^{\circ}$ with ${ }^{\circ}$ low $^{\circ}$ abundance ${ }^{\circ}$ of ${ }^{\circ}$ product ${ }^{\circ}$ ions, ${ }^{\circ}$ which would decrease the sensitivity of the method. This poor fragmentation could be explained by the relatively large size of the sodium cation and its strong interaction with oxygen atoms, which makes the transfer of the cation from one part of the molecule to another difficult. This transfer step is necessary in several fragmentation mechanisms. A possible interpretation of the $[\mathrm{M}+\mathrm{Na}]^{+}$fragmentation is shown in Figure $^{\circ} 3,{ }^{\circ}$ where $^{\circ}$ all $^{\circ}$ product $^{\circ}$ ions $^{\circ}\left(\mathrm{m} / z\right.$ 751.3, ${ }^{\circ} 607.5$, and 449.3 optimized at $45 \mathrm{eV}$, and $\mathrm{m} / \mathrm{z} 183.3$ optimized at $55 \mathrm{eV}$ ) lost at least one monosaccharide group, enhancing selectivity for quantitative determination.

Although no sodium additives were required to obtain the $[\mathrm{M}+\mathrm{Na}]^{+}$ion in infusion experiments, when performing chromatography, the peak obtained for the sodium adduct without using any additive into the mobile phase was smaller than when using the Ion Sabre APCI in negative mode. Thus, it seems that small amounts of $\mathrm{Na}^{+}$have to be added to the chromatographic mobile phase to promote efficient $[\mathrm{M}+\mathrm{Na}]^{+}$ formation. These results contrast with previously reported ${ }^{\circ}$ methods ${ }^{\circ}\left[27,{ }^{\circ} 30,{ }^{\circ} 31\right],{ }^{\circ}$ wherein ${ }^{\circ}$ only ${ }^{\circ}$ one ${ }^{\circ}$ method [27], ${ }^{\circ}$ the $^{\circ}$ adduct $^{\circ}$ formation, ${ }^{\circ}$ was $^{\circ}$ favored ${ }^{\circ}$ by $^{\circ}$ adding sodium acetate to the vial, but sodium salts were not used as additives in the mobile phase in any of them. As Table $^{\circ} 1^{\circ}$ shows, ${ }^{\circ}$ the ${ }^{\circ}$ optimum ${ }^{\circ}$ concentration $^{\circ}$ of $^{\circ}$ sodium acetate in the mobile phase was as low as $10 \mu \mathrm{M}$ because higher additive concentrations led to significant ionization suppression produced by the $\mathrm{Na}^{+}$itself.

Under optimum conditions, an LOD of around 7 $\mu \mathrm{g} / \mathrm{L}$ was obtained, significantly increasing the sensitivity ${ }^{\circ} \mathrm{Compared}^{\circ}$ with $^{\circ} \mathrm{APCI}^{\circ}$ in ${ }^{\circ}$ negative ${ }^{\circ}$ ionization ${ }^{\circ}$ (Figure $\left.{ }^{\circ} 5 \mathrm{a},{ }^{\circ} \mathrm{b}\right) .^{\circ}$ The $^{\circ}$ repeatability ${ }^{\circ}$ of $^{\circ}$ this $^{\circ}$ method $^{\circ}$ was $^{\circ}$ worse than with other approaches tested, although it was still acceptable $\left(14 \%{ }^{\circ}\right.$ Table $\left.^{\circ} 2\right) .^{\circ}$ The $^{\circ} \mathrm{Q} / q$ ratio $^{\circ}$ was $^{\circ}$ close $^{\circ}$ to one, that is, different product ions can be obtained with similar sensitivity, and, therefore, confirmation of positive samples can be performed around the LOD level. These characteristics make this approach suitable for the direct determination of abamectin at the residue level.

No sodium adduct was observed using APCI interfaces, even after the addition of sodium acetate in the infusion solution.

Table 2. Repeatability and ion ratios for the optimal LC-MS/MS conditions

\begin{tabular}{lccc}
\hline API interface/mobile phase & $\begin{array}{c}\text { Quantification }(Q) / \text { confirmation }(q) \\
\text { transitions }\end{array}$ & Q/q Ratio & $\begin{array}{r}\text { RSD (\%) } \\
(n=10)\end{array}$ \\
\hline \hline $\mathrm{APCl}-/ 500 \mu \mathrm{M} \mathrm{Et}{ }_{3} \mathrm{~N}$ & $871.5>229.3 / 871.5>565.3$ & 1.7 & 9 \\
$\mathrm{ESI}+/ 10 \mu \mathrm{M} \mathrm{NaOAc}$ & $895.5>751.3 / 895.5>449.3$ & 1.5 & 14 \\
$\mathrm{ESI}+/ 100 \mu \mathrm{M} \mathrm{NH} \mathrm{OAc}_{4} \mathrm{OAc}$ & $567.3>307.3 / 890.5>567.3$ & 2.9 & 7 \\
$\mathrm{APCl}+/ 500 \mu \mathrm{M} \mathrm{NH}_{4} \mathrm{OAc}$ & $567.3>307.3 / 890.5>567.3$ & 3.3 & 9 \\
$\mathrm{ESI}+/ 10 \mu \mathrm{M} \mathrm{LiOAc}$ & $879.5>151.3 / 879.5>735.5$ & 4.7 & 9 \\
\hline
\end{tabular}




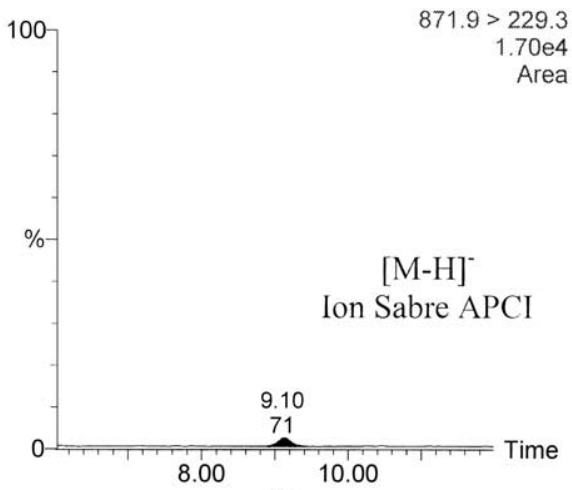

(a)

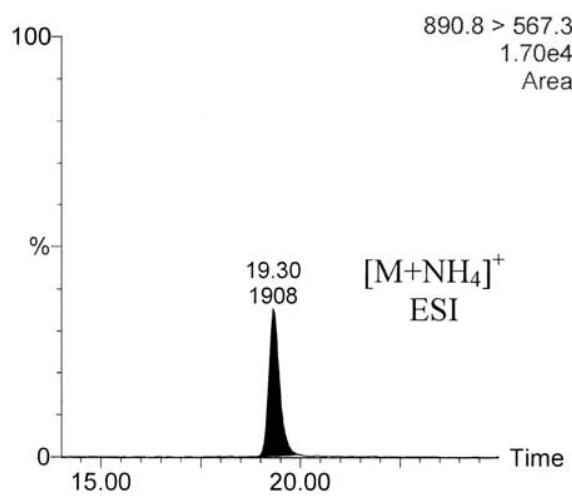

(c)

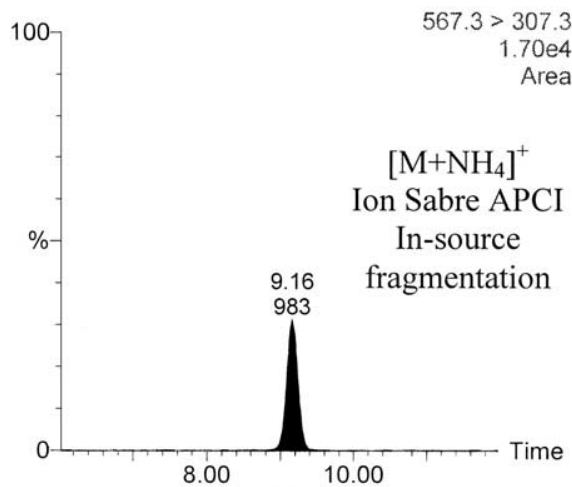

(e)

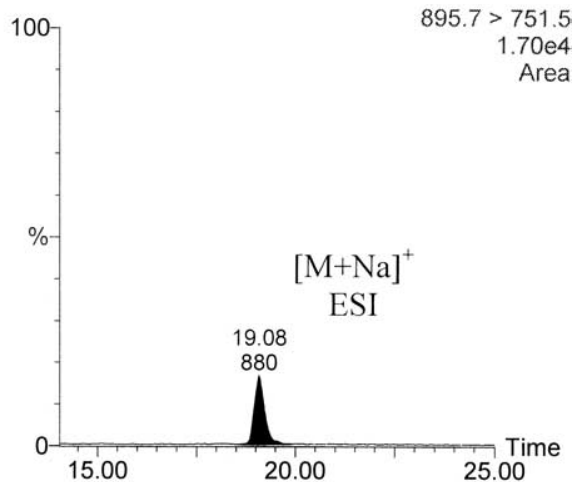

(b)

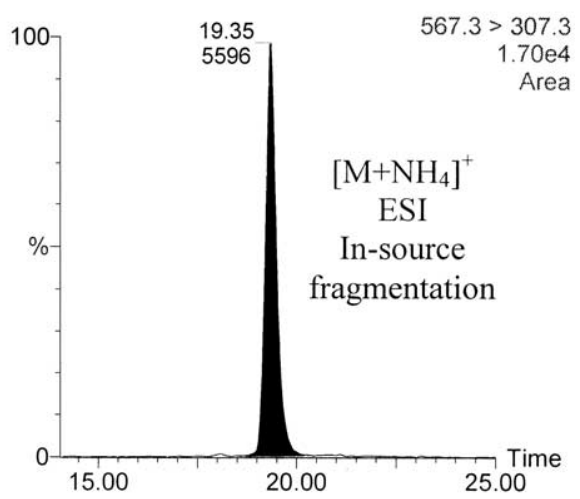

(d)

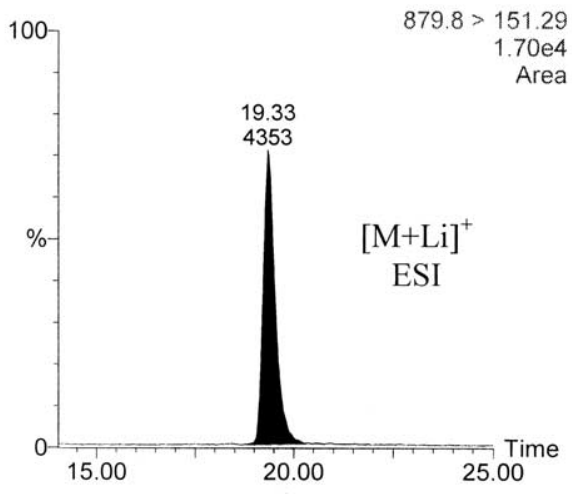

(f)

Figure 5. LC-MS/MS chromatograms for the determination of abamectin in the orange sample extract at $200 \mu \mathrm{g} / \mathrm{L}$ in different conditions. (a) $[\mathrm{M}-\mathrm{H}]^{-}$in negative Ion Sabre APCI $500-\mu \mathrm{M} \mathrm{Et}{ }_{3} \mathrm{~N}$, (b) $[\mathrm{M}+\mathrm{Na}]^{+}$in positive ESI $10-\mu \mathrm{M} \mathrm{NaOAc}$, (c) $\left[\mathrm{M}+\mathrm{NH}_{4}\right]^{+}$in positive ESI $100-\mu \mathrm{M} \mathrm{NH}_{4} \mathrm{OAc}$ using parent adduct as precursor ion, (d) $\left[\mathrm{M}+\mathrm{NH}_{4}\right]^{+}$in positive ESI 100- $\mu \mathrm{M} \mathrm{NH} \mathrm{NH}_{4} \mathrm{OAc}$ using an in-source fragment as precursor ion, (e) $\left[\mathrm{M}+\mathrm{NH}_{4}\right]^{+}$in positive Ion Sabre APCI $500-\mu \mathrm{M} \mathrm{NH} \mathrm{NH}_{4} \mathrm{OAc}$ using an in-source fragment as precursor ion, and $(\mathbf{f})[\mathrm{M}+\mathrm{Li}]+$ in positive ESI $10-\mu \mathrm{M}$ LiOAc.

\section{Ammonium Adducts}

Ammonium adducts were obtained by the addition of 5 $\mathrm{mM}$ of ammonium acetate into the infusion solution. Under these conditions, a peak at $\mathrm{m} / \mathrm{z} 890.5$ corresponding to $\left[\mathrm{M}+\mathrm{NH}_{4}\right]^{+}$was optimized at $25 \mathrm{~V}$ in the ESI interface. The higher affinity of polyoxygenated compounds for $\mathrm{Na}^{+}$than $\mathrm{NH}_{4}^{+}$, gave an abundant $[\mathrm{M}+$ $\mathrm{Na}]^{+}$signal at $\mathrm{m} / \mathrm{z} 895.5$ that was even present after addition $^{\circ}$ of $^{\circ}$ ammonium $^{\circ}$ acetate $^{\circ}\left(\right.$ Figure $\left.^{\circ} 1 \mathrm{c}\right) .^{\circ}$ The $^{\circ}\left[\mathrm{M}^{\circ}+\right.$ $\left.\mathrm{NH}_{4}\right]^{+}$ion was around five times less sensitive than [M
$+\mathrm{Na}]^{+}$; however, the MS/MS spectra of $\left[\mathrm{M}+\mathrm{NH}_{4}\right]^{+}$ presented two abundant fragments $(\mathrm{m} / \mathrm{z} 567.3$ and 305.3 optimized at 15 and $25 \mathrm{eV}$, respectively) with higher relative intensities than those obtained from the sodium adduct. In this case, the lower affinity of the analyte for $\mathrm{NH}_{4}^{+}$may facilitate the fragmentation increasing the sensitivity of the product ions. A possible fragmentation pathway of $\left[\mathrm{M}+\mathrm{NH}_{4}\right]^{+}{ }^{\circ}$ is ${ }^{\circ}$ shown ${ }^{\circ}$ in ${ }^{\circ}$ Figure 4 .

When using ammonium adducts it is relevant that their easy fragmentation allows carrying out in-source 
fragmentation of the $\left[\mathrm{M}+\mathrm{NH}_{4}\right]^{+}$ion by increasing the cone voltage up to $35 \mathrm{~V}$. Under these conditions, an in-source fragment at $\mathrm{m} / \mathrm{z} 567.3$ was obtained, which can be used as precursor ion generating a product ion at $\mathrm{m} / \mathrm{z} 307.3$ (collision energy of $10 \mathrm{eV}$ ). It is remarkable that the product ion at $\mathrm{m} / \mathrm{z} 305.3$ was not observed under these conditions, supporting the hypothesis that both product ions $(\mathrm{m} / \mathrm{z} 305.3$ and 307.3) are obtained from ${ }^{\circ}$ different ${ }^{\circ}$ fragmentation ${ }^{\circ}$ pathways $^{\circ}\left(\right.$ Figure $\left.^{\circ} 4\right)$. $^{\circ}$ This in-source fragmentation was found to be the most sensitive approach when using chromatography, as can be ${ }^{\circ}$ seen ${ }^{\circ} y^{\circ}$ comparison between ${ }^{\circ}$ Figure ${ }^{\circ}{ }^{\circ},{ }^{\circ}$ d, ${ }^{\circ}$ allowing ${ }^{\circ}$ a $\mathrm{LOD}^{\circ}$ of ${ }^{\circ} 2^{\circ} \mu \mathrm{g} / \mathrm{L}^{\circ}\left(\mathrm{Table}^{\circ} 1\right)^{\circ}$ to ${ }^{\circ}$ be $^{\circ}$ reached..$^{\circ} \mathrm{The}^{\circ}$ good sensitivity obtained together with satisfactory precision $\left(\text { Table }^{\circ} 2\right)^{\circ}$ make $^{\circ}$ this ${ }^{\circ}$ approach ${ }^{\circ}$ ideal ${ }^{\circ}$ for ${ }^{\circ}$ development ${ }^{\circ}$ of quantitative methods, the only objection being that confirmation would only be possible at concentrations three times higher than the LOD $(Q / q$ around three). Other ${ }^{\circ}$ authors ${ }^{\circ}[28]^{\circ}$ used $^{\circ}$ several $^{\circ}$ transitions $^{\circ}$ using ${ }^{\circ}$ the parent adduct as precursor ion, with more favorable $Q / q$ ratios, although with lower sensitivity than when using in-source fragmentation.

As opposed to sodium adducts, the $\left[\mathrm{M}+\mathrm{NH}_{4}\right]^{+}$ion also can be formed in the APCI interface. As expected, mass spectrometry conditions, precursor, and product ions were identical to those obtained using the ESI interface. Data obtained with the Ion Sabre APCI allowed us to estimate a sensitivity around 10 times higher than with APCI but still lower (around fivefold

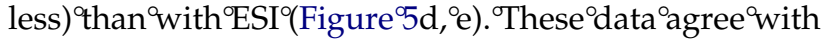
other studies regarding sensitivity obtained with both interfaces, where ESI is preferred because of the better sensitivity ${ }^{\circ}$ reached $^{\circ}[28,029,32]$.

As ${ }^{\circ}$ can ${ }^{\circ}{ }^{\circ}$ seen $1{ }^{\circ}$ Table 1 , the optimum ${ }^{\circ}$ concentration of ammonium acetate in the mobile phase was higher than with the sodium adduct because of the higher volatility of ammonium cation. Furthermore, the optimum concentration was higher in APCI $(500 \mu \mathrm{M})$ than in ESI $(100 \mu \mathrm{M})$, which could be related with the fact that ESI is more affected by ion suppression than APCI $\left[2,{ }^{\circ} 35\right] .{ }^{\circ}$ Much $^{\circ}$ higher $^{\circ}$ concentrations ${ }^{\circ}$ of ${ }^{\circ}$ ammonium ${ }^{\circ}$ ace-

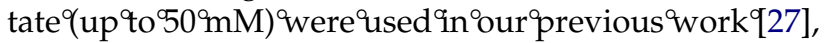
this possibly being the reason for the unsatisfactory results obtained with ammonium adducts.

\section{Lithium Adducts}

The formation of lithium adducts was promoted by the addition of $1 \mathrm{mM}$ of lithium acetate in the infusion solution. Under these conditions, an abundant $[\mathrm{M}+$ $\mathrm{Li}]^{+}$signal at $\mathrm{m} / \mathrm{z} 879.5$ was observed at a cone voltage of $65 \mathrm{~V}$, although the presence of $[\mathrm{M}+\mathrm{Na}]^{+}$ion still was $^{\circ}$ significant $^{\circ}\left(\right.$ Figure $\left.^{\circ} 1 \mathrm{~d}\right) .^{\circ} \mathrm{At}^{\circ}$ low $^{\circ}$ collision $^{\circ}$ energy (lower than $35 \mathrm{eV}$ ) the product ion spectrum of the [M $+\mathrm{Li}^{+}$presented the same behavior as the sodium adduct, showing only a small fragment at $\mathrm{m} / \mathrm{z}$ 735.5. However, for the $[\mathrm{M}+\mathrm{Na}]^{+}$no more abundant fragments were obtained after increasing the collision energy; in the case of $[\mathrm{M}+\mathrm{Li}]^{+}$, two fragments at $\mathrm{m} / \mathrm{z}$
591.5 and 151.3 were obtained at a collision energy of 45 and $50 \mathrm{eV}$, respectively. These fragments, especially the lighter one at $\mathrm{m} / \mathrm{z} 151.3$, were more abundant and therefore more suitable for use in a quantitative method for abamectin residue determination. $\mathrm{Li}^{+}$transfer might be favored more than $\mathrm{Na}^{+}$transfer because of their different size as well as the different affinity of the monosaccharide $^{\circ}$ to ${ }^{\circ}$ both $^{\circ}$ cations. ${ }^{\circ}$ Figure $^{\circ} 3^{\circ}$ shows $^{\circ}$ a possible explanation of the fragments obtained.

When applying this approach after LC, the optimal response was obtained after adding $10 \mu \mathrm{M}$ of LiOAc in the mobile phase achieving an LOD of $3 \mu \mathrm{g} / \mathrm{L}$. The sensitivity was found to be similar to that obtained using ammonium adducts and was notably better to that ${ }^{\circ}$ obtained ${ }^{\circ}$ with $^{\circ}$ sodium $^{\circ}$ adduct $^{\circ}\left(\right.$ Figure $\left.^{\circ} 5 f\right) .{ }^{\circ}$ To $^{\circ}$ our knowledge, there are no quantitative methods developed for the determination of polyoxygenated compounds using lithium adducts. According to our data, the sensitivity achieved, together with satisfactory precision (9\% RSD), show the suitability of using this kind of adduct for this purpose. As in the case of $[\mathrm{M}+$ $\left.\mathrm{NH}_{4}\right]^{+}$, the main drawback of this approach would come from the confirmatory point of view because the

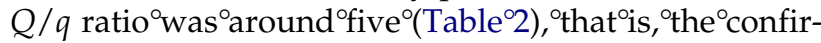
mation only would be possible at concentrations five times higher than the LOD.

As in the case of sodium adduct, no $[\mathrm{M}+\mathrm{Li}]^{+}$signal was obtained by ionization with the APCI interfaces.

\section{Nickel and Cobalt Adducts}

In our search for an alternative to conventional adducts, we checked the use of nickel and cobalt acetate to promote the respective transition-metal adducts. In both cases the results were not satisfactory and no signal was obtained in the ESI source. The formation of these adducts might be explained by the loss of a proton and additional oxygen-metal interactions, generating the species $[\mathrm{M}+\mathrm{Me}-\mathrm{H}]^{+}$, where Me corresponds to the transition ${ }^{\circ}$ metal $^{\circ}\left[21,{ }^{\circ} 25\right] .{ }^{\circ} \operatorname{In}^{\circ}$ the ${ }^{\circ}$ case $^{\circ}$ of ${ }^{\circ}$ abamectin, ${ }^{\circ}$ the absence of the $[\mathrm{M}+\mathrm{Me}-\mathrm{H}]^{+}$ion might be due to the low acidity of the hydroxyl groups as well as to the low conformational flexibility of the macrocyclic structure, which could reduce the oxygen-metal interactions.

\section{Conclusion}

Residue determination of abamectin in complex matrices, such as orange samples, can be performed using different approaches despite the difficulties of abamectin ionization in the API interfaces, although satisfactory results for sensitivity are obtained only after adduct formation.

For sensitivity, two effects have to be taken into account, the affinity of the ions for adduct formation and the abundance of product ions. In this regard the following order was determined: $\left[\mathrm{M}+\mathrm{NH}_{4}\right]^{+}>[\mathrm{M}+$ $\mathrm{Li}^{+}>[\mathrm{M}+\mathrm{Na}]^{+}$. Thus, the best approach seems to be the determination of ammonium adduct by ESI using 
an in-source fragment as a precursor ion. Similar results were obtained for $[\mathrm{M}+\mathrm{Li}]^{+}$, showing the applicability of lithium adducts for efficient quantitative analysis. The optimization of additive concentration was of major importance for achieving maximum sensitivity. To perform confirmative methods, at least two transitions should be monitored. Thus, when fragmentation is focused on a predominant product ion, one transition is notably more sensitive than the others. Under these conditions, the confirmation is troublesome at concentrations close to the LOD of the method. This is the case for $[\mathrm{M}+\mathrm{Li}]^{+}$and $\left[\mathrm{M}+\mathrm{NH}_{4}\right]^{+}$, where the experimental $Q / q$ ratios obtained were around five and three, respectively. In regard to sodium adducts, the confirmation was possible close to LOD level ( $Q / q$ ratio around one), although the sensitivity of the quantitative method was lower. Combining sensitivity of the method and $Q / q$ ratio values, the ammonium adduct allowed confirmation of residues at the lowest concentration levels. Moreover, the use of the Ion Sabre APCI notably increased the sensitivity against conventional APCI, being almost comparable with ESI. ESI was still found to be the most sensitive and therefore more adequate for abamectin residue determination. Owing to the ionization difficulties of this analyte, other interfaces such as atmospheric pressure photoionization (APPI) might be useful for adequate determination. This study shows the versatility and applicability of adduct formation for the determination of noneasily ionizable molecules because up to three reliable methods could be applied to the residue determination of a difficult compound such as abamectin. While with other problematic analytes, each has to be considered individually to achieve the optimum experimental conditions, the results found here provide an interesting possibility for the investigation of analytical solutions.

\section{Acknowledgments}

The Quattro Micro LC-MS/MS was funded by the European Union (Fondos Feder-Reino de España, Ministerio de Ciencia y Tecnología, Ref. UNJM-E004). The authors are grateful to Ramesh Rao (Waters) for his valuable comments. They also thank the two anonymous reviewers, whose comments greatly improved this work.

\section{References}

1. Careri, M.; Mangia, A. Multidimensional Detection Methods for Separations and Their Application in Food Analysis. Trends. Anal. Chem. 1996, 15, 538-550.

2. Thurman, E. M.; Ferrer, I.; Barceló, D. Choosing between Atmospheric Pressure Chemical Ionization and Electrospray Ionization Interfaces for the HPLC/MS Analysis of Pesticides. Anal. Chem. 2001, 73, 5441-5449.

3. Niessen, W. M. A. State-of-Art in Liquid ChromatographyMass Spectrometry. J. Chromatogr. A 1999, 856, 179-197.

4. Barceló, D. Applications of LC-MS in Environmental Chemistry; Elsevier Science B.V.: Amsterdam, 1996.
5. Picó, Y.; Font, G.; Moltó, J.C.; Mañes, J. Pesticide Residue Determination in Fruit and Vegetables by Liquid Chromatography-Mass Spectrometry. J. Chromatogr. A 2000, 882, 153-173.

6. Moret, S.; Conte, L. S. Polycyclic Aromatic Hydrocarbons in Edible Fats and Oils: Occurrence and Analytical Methods. J. Chromatogr. A 2000, 882, 245-253.

7. Van der Hoff, G. R.; van Zoonen, P. Trace Analysis of Pesticides by Gas Chromatography. J. Chromatogr. A 1999, 843, 301-322.

8. Pitarch, E.; Serrano, R.; López, F. J.; Hernández, F. Rapid Multiresidue Determination of Organochlorine and Organophosphorus Compounds in Human Serum by Solid-Phase Extraction and Gas Chromatography Coupled to Tandem Mass Spectrometry. Anal. Bioanal. Chem. 2003, 376, 189-197.

9. Elliott, C. T.; Kennedy, D. G.; Mc Caughey, W. J. Methods for the Detection of Polyether Ionophore Residues in Poultry. Analyst 1998, 123, 45R-56R.

10. Turnipseed, S. B.; Roybal, J. E.; Rupp, H. S.; Gonzales, S. A.; Pfenning, A. P.; Hurlbut, J. A. Confirmation of Avermectin Residues in Food Matrices with Negative-ion Atmospheric Pressure Chemical Ionization Liquid Chromatography/Mass Spectrometry. Rapid. Commun. Mass. Spectrom. 1999, 13, 493 499.

11. Wu, Z.; Li, J.; Zhu, L.; Luo, H.; Xu, X. Multi-Residue Analysis of Avermectins in Swine Liver by Immunoaffinity Extraction and Liquid Chromatography-Mass Spectrometry. J. Chromatogr. A 2001, 755, 361-366.

12. Howells, L.; Sauer, M. J. Multi-Residue Analysis of Avermectins and Moxidectin by Ion-Trap LC-MS ${ }^{n}$. Analyst 2001, 126, 155-160.

13. Harvey, D. J. Electrospray Mass Spectrometry and Fragmentation of N-Linked Carbohydrates Derivatized at the Reducing Terminus. J. Am. Soc. Mass Spectrom. 2000, 11, 900-915.

14. Lopes, N. P.; Stark, C. B. W.; Hong, H.; Gates, P. J.; Staunton, J. Fragmentation Studies on Monesin A by Sequential Electrospray Mass Spectrometry. Analyst 2002, 127, 503-506.

15. Harris, J. A.; Russell, C. A. L.; Wilkins, J. P. G. The Characterization of Polyether Ionophore Veterinary Drugs by HPLCElectrospray MS. Analyst 1998, 123, 2625-2628.

16. Mortier, K. A.; Zhang, G. F.; Van Peteghem, C. H.; Lambert, W. E. Adduct Formation in Quantitative Bioanalysis: Effect of Ionization Conditions on Placlitaxel. J. Am. Soc. Mass Spectrom. 2004, 15, 585-592.

17. Kuuranne, T.; Vahermo, M.; Leinonen, A.; Kostiainen, R. Electrospray and Atmospheric Pressure Chemical Ionization Tandem Mass Spectrometric Behavior of Eight Anabolic Steroid Glucuronides. J. Am. Soc. Mass Spectrom. 2000, 11, 722730.

18. Byrdwell W. C.; Neff, W. E. Dual Parallel Electrospray Ionization and Atmospheric Pressure Chemical Ionization Mass Spectrometry (MS), MS/MS, and MS/MS/MS for the Analysis of Triacylglycerols and Triacylglycerol Oxidation Products. Rapid. Commun. Mass Spectrom. 2002, 16, 300-319.

19. Volmer, D. A.; Lock, C. M. Electrospray Ionization and Collision-induced Dissociation of Antibiotic Polyether Ionophores. Rapid. Commun. Mass Spectrom. 1998, 12, 157-164.

20. Levery, S. B.; Toledo, M. S.; Straus, A. H.; Takahashi, H. K. Comparative Analysis of Glycosylinositol Phosphorylceramides From Fungi by Electrospray Tandem Mass Spectrometry With Low-Energy Collision-Induced Dissociation of $\mathrm{Li}^{+} \mathrm{Ad}-$ duct Ions. Rapid. Commun. Mass Spectrom. 2001, 15, 2240-2258.

21. Chen, R.; Li, L. Lithium and Transition Metal Ions Enable Low Energy Collision-Induced Dissociation of Polyglycols in Electrospray Ionization Mass Spectrometry. J. Am. Soc. Mass Spectrom. 2001, 12, 832-839. 
22. Harvey, D. J. Collision-Induced Fragmentation of Underivatized N-Linked Carbohydrates Ionized by Electrospray. J. Mass Spectrom. 2000, 35, 1178-1190.

23. Harvey, D. J. Ionization and Fragmentation of N-Linked Glycans as Silver Adducts by Electrospray Mass Spectrometry. Rapid. Commun. Mass Spectrom. 2005, 19, 484-492.

24. Harvey, D. J. Ionization and Collision-induced Fragmentation of N-Linked and Related Carbohydrates Using Divalent Cations. J. Am. Soc. Mass Spectrom. 2001, 12, 926-937.

25. Leavell, M. D.; Leary, J. A. Stabilization and Linkage Analysis of Metal-Ligated Sialic Acid Containing Oligosaccharides. J. Am. Soc. Mass Spectrom. 2001, 12, 528-536.

26. Gaucher, S. P.; Leary, J. A. Stereochemical Differentiation of Mannose, Glucose, Galactose, and Talose Using Zinc (II) Diethylenetriamine and ESI-Ion Trap Mass Spectrometry. Anal. Chem. 1998, 70, 3009-3014.

27. Pozo, O. J.; Marin, J. M.; Sancho, J. V.; Hernández, F. Determination of Abamectin and Azadirachtin Residues in Orange Samples by Liquid Chromatography-Electrospray Tandem Mass Spectrometry. J. Chromatogr. A 2003, 992, 133-140.

28. Zywitz, D.; Anastassiades, M.; Scherbaum, E. Simultaneous Determination of Macrocyclic Lactone Insecticides in Fruits and Vegetables using LC-MS/MS. Deutsche. LebensmittelRundshau. 2004, 100, 140-150.

29. Pereira, T.; Chang, S. W. Semi-Automated Quantification of Ivermectin in Rat and Human Plasma Using Protein Precipitation and
Filtration With Liquid Chromatography/Tandem Mass Spectrometry. Rapid. Commun. Mass Spectrom. 2004, 18, 1265-1276.

30. Croubels, S.; De Baere, S.; Cherlet, M.; De Backer, P. Determination of Ivermectin $B_{1 a}$ in Animal Plasma by Liquid Chromatography Combined With Electrospray Ionization Mass Spectrometry. J. Mass Spectrom. 2002, 37, 840-847.

31. Valenzuela, A. I.; Redondo, M. J.; Picó, Y.; Font, G. Determination of Abamectin in Citrus Fruits by Liquid Chromatography-Electrospray Ionization Mass Spectrometry. J. Chromatogr. A 2000, 871, 57-65.

32. Ali, M. S.; Sun, T.; Mc Leroy, G. E.; Phillippo, E. T. Confirmation of Eprinomectin, Moxidectin, Abamectin, Doramectin, and Ivermectin in Beef Liver by Liquid Chromatography/Positive Ion Atmospheric Pressure Chemical Ionization Mass Spectrometry. J. AOAC Int. 2000, 83, 39-52.

33. Ballard, J. M.; Payne, L. D.; Egan, R. S.; Wehner, T. A. Development and Validation of an HPLC/MS/MS Method for the Confirmation of Eprinomectin Marker Residue in Bovine Liver Tissue. J. Agric. Food. Chem. 1997, 45, 3507-3510.

34. Commission Decision 2002/657/CE of 12 August 2002.

35. Matuszewski, B. K.; Constanzer, M. L.; Chavez-Eng, C. M. Matrix Effect in Quantitative LC/MS/MS Analyses of Biological Fluids: A Method for Determination of finasteride in Human Plasma at Picogram Per Mililiter Concentration. Anal. Chem. 1998, 70, 882-889. 